\title{
Chorismate synthase from Staphylococcus aureus
}

\author{
Malcolm J. Horsburgh, ${ }^{1} \dagger$ Timothy J. Foster, ${ }^{2}$ Peter T. Barth ${ }^{3}$ \\ and John R. Coggins ${ }^{1}$
}

Author for correspondence: John R. Coggins. Tel: +44 141330 5267. Fax: +44 1413304620.
e-mail: J.Coggins@bio.gla.ac.uk

1 Division of Biochemistry \& Molecular Biology,

Institute of Biomedical \&

Life Sciences, University of Glasgow, Glasgow G12 8QQ, UK

2 Microbiology Department, Moyne Institute of

Preventive Medicine,

Trinity College, Dublin 2, Ireland

3 Department of Infection Research, Zeneca Pharmaceuticals, Alderley Park, Macclesfield, Cheshire SK10 4TG, UK

The aroC gene encoding chorismate synthase and the ndk gene encoding nucleoside diphosphate kinase (Ndk) were cloned from Staphylococcus aureus. DNA sequencing suggests that aro $C$ is located in an operon with aroB and aroA and encodes a protein of 388 amino acids with $61 \%$ identity to the arof gene product of Bacillus subtilis. The ndk gene of $S$. aureus encodes a protein of 149 amino acids which exhibits a high degree of identity to other bacterial Ndk proteins. The 3' end of the $S$. aureus gercC gene was also identified by sequencing and was located immediately upstream of ndk. The gerCA and gerCB genes were found to be located upstream of gerCC by Southern hybridization analysis. This observed linkage of the gerC genes with the ndk, aro $C$ and aroB genes has been similarly observed in B. subtilis. The $S$. aureus chorismate synthase was overexpressed to a high level in Escherichia coli using a $\mathrm{T7}$ promoter plasmid construct, the enzyme was purified to near homogeneity in two steps and found to be a homotetramer with a subunit molecular mass, estimated by electrospray mass spectrometry, of $43024 \mathrm{Da}$. The properties of $S$. aureus chorismate synthase are compared with those of the B. subtilis and $E$. coli enzymes.

Keywords: Staphylococcus aureus, chorismate synthase, nucleoside diphosphate kinase

\section{INTRODUCTION}

In micro-organisms and plants, chorismic acid is a central precursor for the biosynthesis of an array of biochemically important and structurally diverse aromatic compounds. These include folic acid, vitamin $\mathrm{K}$, ubiquinone and the three aromatic amino acids (Bentley, 1990; Haslam, 1993). Chorismate synthase (EC 4.6.1.4), the seventh enzyme in the pre-chorismate (shikimate) pathway, catalyses the conversion of 5-enolpyruvylshikimate 3-phosphate (EPSP) to chorismate. The reaction involves the abstraction of the C-(6pro-R)-hydrogen with the concomitant elimination of phosphate to generate the second double bond of the aromatic ring. Chorismate synthase has been studied to a varying extent in a number of microorganisms and plants, including Escherichia coli (White et al., 1988; Ramjee et al., 1991; Bornemann et al., 1995),

\footnotetext{
Abbreviation: EPSP, 5-enolpyruvylshikimate 3-phosphate.

†Present address: Department of Molecular Biology and Biotechnology, University of Sheffield, Western Bank, Sheffield S10 2TN, UK.

The Genbank accession number for the sequence data reported in this paper is U31979.
}

Bacillus subtilis (Hasan \& Nester, 1978), Neurospora crassa (Gaertner \& Cole, 1973; White et al., 1988; Henstrand et al., 1995), Euglena gracilis (Schaller et al., 1991), Pisum sativum (Mousdale \& Coggins, 1986) and Corydalis sempervirens (Schaller et al., 1990). Chorismate synthase from these species has an absolute requirement for a reduced flavin cofactor, although the conversion of EPSP to chorismate is not accompanied by a net overall change in redox state. The enzymes differ, however, in their ability to generate the reduced flavin cofactor. The $N$. crassa enzyme posesses an intrinsic NADPH-dependent flavin reductase activity (Gaertner \& Cole, 1973; Henstrand et al., 1995), while flavin reductase forms part of a complex with chorismate synthase in both $B$. subtilis and $E u$. gracilis.

The enzymes of the aromatic biosynthetic pathway are attractive targets for inhibitors since this pathway is absent in mammals. (6S)-6-Fluoroshikimic acid has been shown to be converted in vivo by the pre-chorismate pathway enzymes to ultimately produce inhibition of $p$ aminobenzoic acid (PABA) synthesis, and thus folic acid production (Davies et al., 1994; Ewart et al., 1995). Mutants defective in the pre-chorismate pathway have 
vaccine potential. Aromatic-dependent (aro) mutants of the pathogenic bacteria Salmonella spp. (Hoiseth \& Stocker, 1981; Jones et al., 1991), Bordetella pertussis (Roberts et al., 1990), Yersinia enterocolitica (Bowe et al., 1989), Bacillus anthracis (Ivins et al., 1990) and Aeromonas salmonicida (Vaughan et al., 1993) have been shown to be avirulent and stimulate protective immunity.

This paper reports the molecular cloning, sequencing and expression of the aro $C$ and $n d k$ genes and the purification and properties of chorismate synthase from Stapbylococcus aureus.

\section{METHODS}

Bacterial strains, plasmids and media. E. coli K-12 GLW40 (aroC thi $\operatorname{rec} A 13$ ) (AB2849 made $\operatorname{rec} A$ ) and $E$. coli $\mathrm{AB} 1321$ (pro $A 2$ aro $A 2$ bis- 4 thi-1 lac $Y 1$ ) were used as hosts for aro $C$ and aro $A$ complementation experiments, respectively (Pittard \& Wallace, 1966). E. coli K-12 DH5 $\alpha$ (end $A 1$ bsdR 17 supE44 rec $A 1$ gyr $A 96$ relA1 $\phi 80$ lacZLM15 thi) was used as a host for pBluescript and pUC vectors. E. coli BL21(DE3) (bsdS gal [ imm $^{21}$ Sam7 nin5 lac UV5-T7 gene1]) and GLW40(DE3) were used for expression of genes cloned under T7 promoter control. GLW40(DE3) was prepared using a commercially available lysogenization kit (Novagen Inc.). S. aureus 601055 was a clinical isolate obtained from Zeneca Pharmaceuticals culture collection. Plasmids pBluescript SKII (Short et al., 1988) and pUC18 (Yanisch-Perton et al., 1985) were used as general cloning vectors. Plasmid pCOC102 contains the aro AaroB genes of $S$. aureus 8325-4 in pUC18 (O'Connell et al., 1993). Plasmid pMAY1 contains the gerCAgerCBgerCC genes of $B$. subtilis 1604 in pUC119 (Yazdi, 1991). The expression vector pTB361 contains the T7 promoter (Brockbank \& Barth, 1993). E. coli and S. aureus strains were grown in LB broth or on LB-agar at $37^{\circ} \mathrm{C}$. Antibiotics were incorporated at the following concentrations: ampicillin, $100 \mu \mathrm{g} \mathrm{ml} l^{-1}$; chloramphenicol, $17 \mu \mathrm{g} \mathrm{ml} \mathrm{m}^{-1}$; tetracycline, $12.5 \mu \mathrm{g} \mathrm{ml}^{-1}$. Screening for complementation of the aromatic deficiencies of E. coli strains GLW40 and AB1321 was performed on M9 minimal medium agar supplemented with amino acids and vitamins as appropriate.

Molecular cloning and DNA manipulation. Chromosomal DNA was purified from $S$. aureus after cell lysis with lysostaphin $\left(100 \mu \mathrm{g} \mathrm{ml}^{-1}\right)$ followed by phenol and chloroform extractions (Sambrook et al., 1989). Plasmid DNA was isolated by the method of Holmes \& Quigley (1981) except if required for DNA sequencing when Qiagen columns were used. DNA was restricted and analysed using standard procedures (Sambrook $e t$ al., 1989). Restriction enzymes were from New England Biolabs or Promega. DNA blotted onto Hybond-N (Amersham) was hybridized against radiolabelled DNA using standard methods. DNA probes were prepared using a Megaprime kit (Amersham) incorporating $\left[\alpha^{32} \mathrm{P}\right] \mathrm{dATP}$. Homologous probes were washed with $0.1 \times$ SSC $(1 \times$ SSC is $0.15 \mathrm{M} \mathrm{NaCl}, 0.015 \mathrm{M} \mathrm{Na}$ citrate $)$ at $65{ }^{\circ} \mathrm{C}$ following hybridization. Reduced stringency conditions for heterologous probing with the gerC genes from B. subtilis was achieved by probing at $50^{\circ} \mathrm{C}$ in $6 \times \mathrm{SSC}$ followed by washes at $50^{\circ} \mathrm{C}$ in $2 \times \mathrm{SSC}$. The $\operatorname{gerC}$ fragments used as heterologous probes were obtained from digestion of pMAY1 and included a 2252 bp HindIII gerC AgerCBgerCC fragment, a 1215 bp HindIII-SspI gerC AgerCB fragment, a 452 bp HindIII$N s i$ gerC $A$ fragment and an 843 bp DraI-HindIII gerCC fragment.

PCR amplification of aroC. The coding region of the aro $C$ gene was amplified from $S$. aureus genomic DNA using VENT polymerase (New England Biolabs) and the two synthetic oligonucleotide primers CHOR 34 (5' GGCATATGAGATACCTAACATCAGGA $\left.3^{\prime}\right)$ and CHOR 35 (5' GGAGATCTTAAAACTCTAATTATAAGTT $3^{\prime}$ ) which contained NdeI and $B g / I I$ restriction sites, respectively. Amplification was performed with $2.5 \mathrm{U}$ polymerase, $100 \mathrm{pmol}$ primers, $30 \mu \mathrm{M}$ each dNTP and $100 \mathrm{ng}$ DNA. The amplified gene was cloned into the NdeI$\mathrm{Bg} / \mathrm{II}$ sites of pTB361 to form pMJH7EX2 and sequenced to verify the absence of errors.

DNA sequencing. DNA was sequenced on both strands using synthetic oligonucleotide primers on denatured doublestranded plasmid DNA by the method of Sanger et al. (1977) Synthetic oligonucleotides around $250 \mathrm{bp}$ apart along the template were designed to prime sequencing reactions.

Protein overexpression and $\mathbf{N}$-terminal sequencing. Protein expression from bacterial cultures of E. coli strains BL21(DE3) and GLW40(DE3) containing the plasmid pM JH7EX2 were examined by SDS-PAGE (Studier \& Moffatt, 1986); gels were stained with Coomassie brilliant blue R-250. N-terminal protein sequencing was performed by Edman degradation (Applied Biosystems protein sequencer) after blotting the protein onto PVDF membrane (Applied Biosystems) (Matsudaira, 1987) .

Western blotting of $S$. aureus chorismate synthase. Crude extracts of $E$. coli containing $S$. aureus chorismate synthase and E. coli chorismate synthase expressed from pMJH7EX2 and pGM605 (White $e t$ al., 1988), respectively, were separated by SDS-PAGE. The gel was blotted onto nitrocellulose membrane and blocked with Tris-buffered saline and $0.5 \%(\mathrm{v} / \mathrm{v})$ Tween 20. Immunodetection was performed with polyclonal rabbit anti-chorismate synthase antibody raised against denatured $E$. coli enzyme and $5 \%$ polyclonal donkey serum (SAPU). Donkey anti-rabbit immunoglobulin $G$ horse-radish peroxidase conjugate (SAPU) was used as secondary antibody and chloronaphthol solution used for development.

Purification of $S$. aureus chorismate synthase. $S$. aureus chorismate synthase was purified from E. coli GLW40(DE3)(pMJH7EX2) using two chromatographic steps (DEAE-Sephacel and cellulose phosphate) essentially as described by White $e t$ al. (1988).

Step 1: DEAE-Sephacel. Cells (13 $\mathrm{g}$ wet wt) were suspended in extraction buffer $(50 \mathrm{mM}$ Tris/ $\mathrm{HCl}, \mathrm{pH} 7 \cdot 5,50 \mathrm{mM} \mathrm{KCl}$, $1 \mathrm{mM}$ benzamidine, $1.2 \mathrm{mM}$ PMSF, $1.3 \mathrm{mM}$ EDTA, $0.4 \mathrm{mM}$ DTT, $20 \%, \mathrm{v} / \mathrm{v}$, glycerol) and broken by two passages through a French pressure cell [950 p.s.i. (6.55 MPa)]. This material was centrifuged at $28000 \mathrm{~g}$ for $30 \mathrm{~min}$ and the supernatant (crude extract) loaded onto a DEAE-Sephacel (Pharmacia) column $(100 \mathrm{ml}$ bed volume) equilibrated in buffer A (extraction buffer minus benzamidine). The column was first washed with buffer A, then eluted with a linear gradient $(600 \mathrm{ml})$ of $50-500 \mathrm{mM}$ $\mathrm{KCl}$ in buffer $\mathrm{A}$. Fractions containing chorismate synthase were pooled and dialysed overnight against buffer $\mathrm{B}(10 \mathrm{mM}$ potassium phosphate, $\mathrm{pH} 6.6,0.45 \mathrm{mM}$ PMSF, $1.3 \mathrm{mM}$ EDTA, $0 \cdot 4 \mathrm{mM}$ DT'T, $20 \%$ glycerol).

Step 2: Cellulose phosphate. The dialysed protein from the previous step was loaded onto a cellulose phosphate (Whatman P11) column ( $60 \mathrm{ml}$ bed volume). The column was first washed with buffer $B$, then eluted with a linear gradient $(400 \mathrm{ml})$ of $10-400 \mathrm{mM}$ potassium phosphate in buffer B. Fractions containing chorismate synthase were precipitated with the addition of solid $\left(\mathrm{NH}_{4}\right)_{2} \mathrm{SO}_{4}$ and protein recovered by spinning at $28000 \mathrm{~g}$ for $30 \mathrm{~min}$. The enzyme was resuspended in $50 \mathrm{mM}$ Tris $/ \mathrm{HCl}, \mathrm{pH} 7 \cdot 5$, containing $50 \%$ glycerol and $1 \mathrm{mM}$ DTT and stored at $-20^{\circ} \mathrm{C}$. This preparation was stable for 6 months with no apparent loss of chorismate synthase activity. 
Enzyme assay. Chorismate svnthase from S. aureus was assayed anaerobically at $25^{\circ} \mathrm{C}$ using the method of Ramjee et al. (1994). Assay buffer consisted of $50 \mathrm{mM}$ MOPS, pH $7 \cdot 0,100 \mathrm{mM} \mathrm{NaCl}$, $25 \mu \mathrm{M}$ FMN and $50 \mu \mathrm{M}$ EPSP.

Protein estimation. Protein in crude samples was determined by the method of Bradford (1976) and in purified samples by the method of Gill \& von Hippel (1989) using a calculated extinction coefficient for the $S$. aureus chorismate synthase of $23100 \mathrm{M}^{-1} \mathrm{~cm}^{-1}$.

Gel filtration and electrospray mass spectrometry. The native molecular mass of $S$. aureus chorismate synthase was estimated using a Superose $12 \mathrm{gel}$ permeation chromatography column (Pharmacia) with comparison to enzymes of known molecular mass as described by Walker et al. (1996). The subunit molecular mass was determined using electrospray mass spectrometry as described by Krell et al. (1995).

\section{RESULTS AND DISCUSSION}

\section{Cloning of the aroC gene}

Chromosomal DNA from S. aureus 601055 was digested with a number of restriction enzymes and blotted onto Hybond-N membrane (Amersham). This was probed with a $350 \mathrm{bp}$ EcoRI-HindIII aroC fragment from pCOC102 which contains the complete aro AaroB genes from S. aureus 8325-4 (O'Connell et al., 1993). A $5.5 \mathrm{~kb}$ Clal fragment was observed after hybridization. The Aro phenotype of E. coli strain GLW40 was then complemented using a ClaI plasmid library and 12 clones were isolated. Each was found to have obvious restriction map similarities with pCOC102 and one plasmid, pMJH701, was studied further. This plasmid was also shown to complement the Aro phenotype of AB1321.

\section{Sequencing of the aroC clone}

A $2.5 \mathrm{~kb} \mathrm{NdeI-ClaI} \mathrm{fragment} \mathrm{from} \mathrm{pMJH701} \mathrm{(Fig.} \mathrm{1)}$ was cloned into $N$ deI-AccI-digested pUC18, forming pMJH702, and the DNA sequence of the $2.5 \mathrm{~kb}$ insert was determined. The DNA sequence, which has a GC content of $33 \%$, is shown in Fig. 2. Two complete ORFs were located by DNA sequencing. The predicted polypeptide from the larger of the two ORFs consisted of 388 amino acids and had $61 \%$ identity with the aroF gene product of B. subtilis and $37 \%$ identity with the aro $C$ gene product of E. coli, both of which have chorismate synthase activity. A putative promoter and ribosome binding site were located upstream from the ATG start codon of the aro $C$ gene. The second complete ORF was situated some 500 bp upstream from aro $C$ and the predicted polypeptide from this consisted of 149 amino acids and had $62 \%$ and $45 \%$ identity with the ndk gene products from $B$. subtilis and $E$. coli, respectively. Contained within the $2.5 \mathrm{~kb}$ of DNA sequenced in pMJH702 were two partial ORFs. Situated 25 bp downstream from the TAA stop codon of aro $C$ was the 5 ' end of an ORF which had homology with the aroB gene, encoding 3-dehydroquinate synthase, from $B$. subtilis. The $3^{\prime}$ end of the second partial ORF immediately
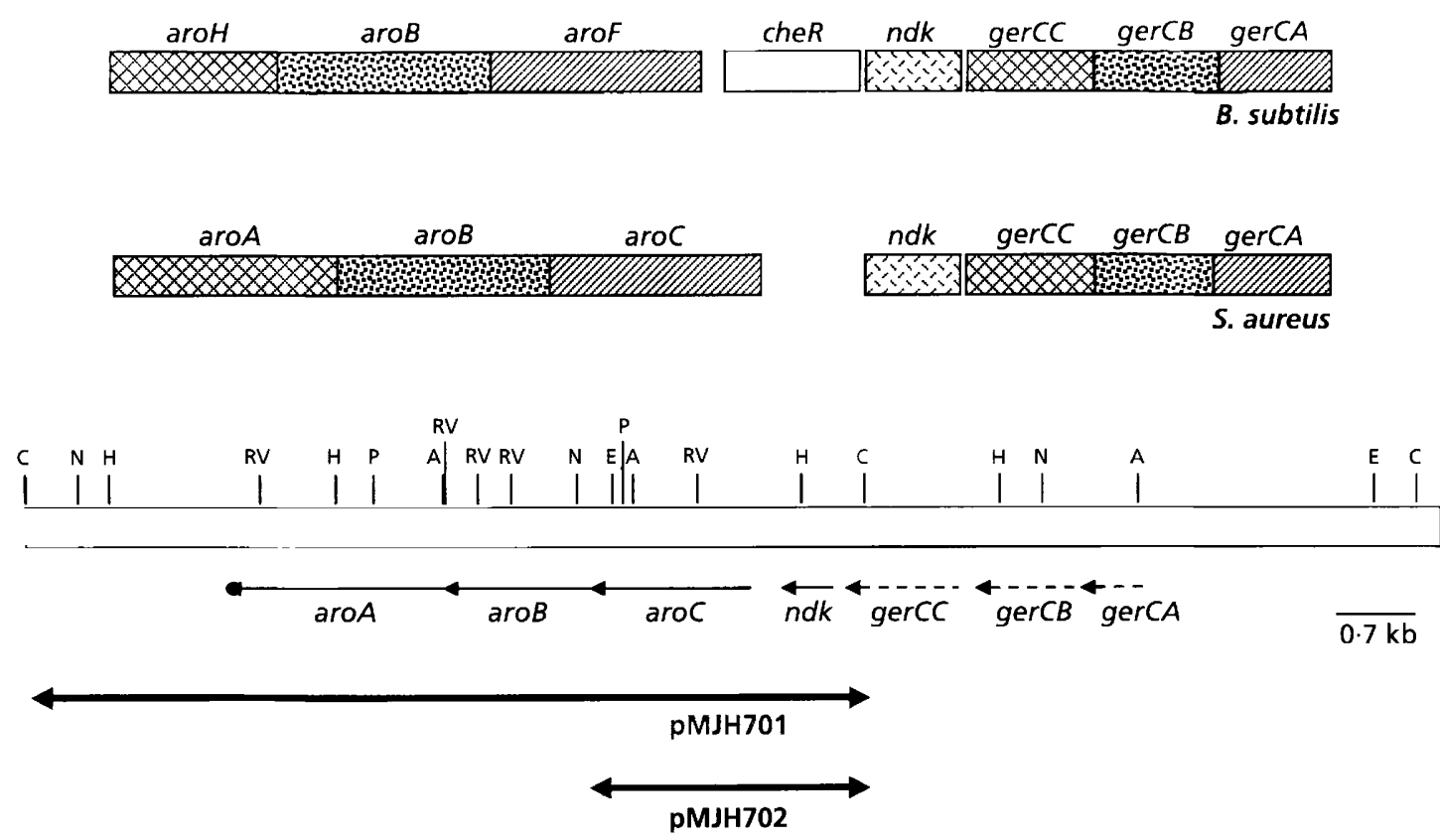

Fig. 1. Combined schematic map of the ger $C, n d k$, aro region of the $S$. aureus chromosome. The positions of the $n d k$ and aro genes were deduced from DNA sequencing data presented here and from previous analysis (O'Connell et al., 1993). The positions of the gerC genes are shown by dashed arrows, indicating approximate locations based on hybridization analysis data presented here and from B. subtilis sequences (Henner, 1992). The map indicates the $5.5 \mathrm{~kb}$ Clal fragment inserted in pMJH701 and the $2.5 \mathrm{~kb}$ Ndel-Clal fragment subcloned to form pMJH702. The clones were mapped with a number of restriction endonucleases. A, Accl; C, Clal; E, EcoRI; RV, EcoRV; H, HindIII; N, Ndel; P, Pstl. 
ATCGATGAAGCTAAGGCAGTAAGTTCGAAGTATCTAAGTAAAGCTTTGGATTTGATTTCTGAGTTGCCAGATGGACATCCAAAATCACTACTTTTAAGTTTGACGAAAAAAATGGGTCA

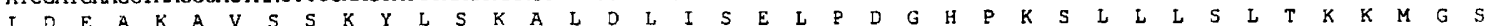

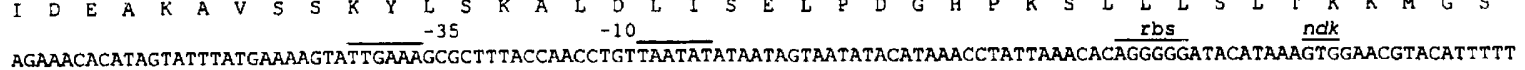
R N T .

AATGATTAAACCAGACGCAGTACAAAGAAATCTAATTGG TGAAGTAATTTCAAGAATTGAAGGAAAGGACTAAAACTTGTCGGTGGTAAATTAATGCAAGTACCAATGGAACTTGCTGA

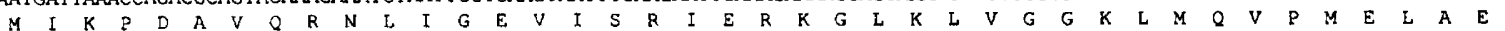
AACACATTATGGTGAACACCAAGGTAAACCATITTATAATGATTTAATTTCATTTATTACATCAGCACCAGTGTTCGCAATGGTAGTTGAAGGTGAAGATGCAGTTAATGTATCTAGACA

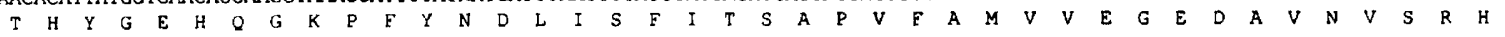
TATTATTGGCAGCACCAATCCTrCAGAAGCTTCACCAGGATCAATTAGAGGTGATTTAGGTTTAACTGTTGGTAGAAATATCATTCACGGTTCAGATTCATTAGAGTCTGCTGAACGTGA

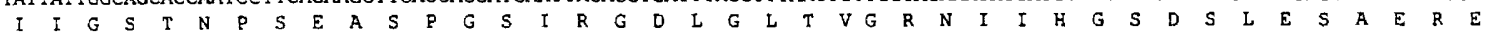
AATTAATTATGGTTTAATGAAAATGAAATTACTAGCTATGCTTCACCACGTGATGCTTGGTTATACGAATAAAATATAAGCTATAAATCTTTCTGATTTATAAAAGGAAAAAGGTTTT

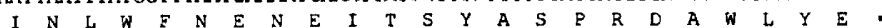

GTTATGTGGTTAGTGATTGATGACCATTCATAACAAAGCCCTATTTTTATACGGACTGATTAACTTTATAAAAAATAATCAGTCCATTTTCTTTTATTTAAAGAAATATAGCTTGTATAT TATTTATTCGTGGTTAGCTACGATTATATGCGGTATAAGTTGTTCGAATAAATT TTAAATTTTCAAATGGTTGTTTAAACAATCTAACAATATTAGAAATTCATAATACTTTTCTCGTTG IGAATATATTATAATGAATCTTAGTTCGTTTAATATTAAGATAATTCTGACATT TAAAAAGAGATATAAATCAATTTCTTAATTGAGCTTGAAAACAAACATTTATGAATGCACAATGAA

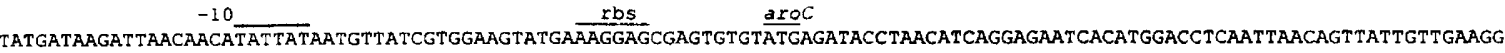

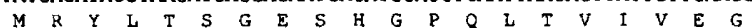

IGTACCTGCAAATTTAGAAGTTAAGGTTGAGGATATTAATAAAGAAATGTTTAAGCGTCAAGGCGGTTACGGACGTGGACGTCGTATGCAAATTGAAAAAGATACAGTGGAGATTGTTTC $\begin{array}{lllllllllllllllllllllllllllllllllllllllllllllllll}V & P & A & N & L & E & V & K & V & E & D & I & N & K & E & M & F & K & R & Q & G & G & Y & G & R & G & R & R & M & Q & I & E & K & D & T & V & E & I & V & S\end{array}$ GGGTGTAAGAAATGGTTATACATTAGGTAGCCCTATTACAATTGTTGTTACTAATGATGATTTMACACATTGGCGAAAATTATGGGCCGTGCGCCAATAAGCGACGAAGAACGAGAAAA 1440

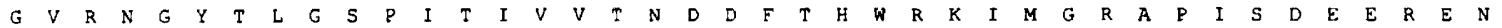
TATGAAACGTACAATTACGAAGCCAAGACCGGGACATGCAGATTTAGTTGGCGGTATGAAATATAATCATCGTGACTTACGAAATGTATTAGAACGTTCATCTGCCAGAGAAACAGCAGC IS60

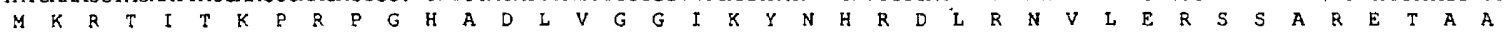
ACGTGTAGCGGTCGGTGCACTATGCAAAGTTTTATTAGAACAATTAGATATCGAAATATACAGTCGTGTTGTTGAGATAGGTGGCATTAAAGATAAAGATTTTTATGATTCAGAAACATT 168

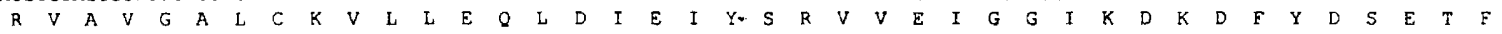
TAAAGCAAACCTTGATCGAAATGACGTCCGTGTAATTGATGATGGCATCGCACAAGCAATGCGCGATAAAATTGATGAAGCGAAAAACGATGGTGATTCAATAGGGGGCGTAGTTCAAGT 1 BO $\begin{array}{lllllllllllllllllllllllllllllllllllllllllllll}K & A & N & L & D & R & N & D & V & R & V & I & D & D & G & I & A & Q & A & M & R & D & K & I & D & E & A & K & T & D & G & D & S & I & G & G & V & V & Q & V\end{array}$ TGTAGTTGAAAATATGCCTGTTGGTGTAGGTAGTTATGTACATTATGATCGTAAATTAGATGGAAGAATAGCACAGGGTGTCGTTAGTATTAATGCATTTAAAGGTGTAAGTTTTGGAGA I92

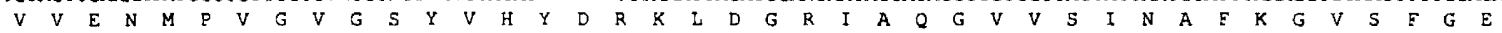
AGGATTTAAAGCAGCTGAAAAGCCTGGTAGCGAATTCAAGACGAAATTCTCTACAATACTGAATTGGGCTATTATCGTGGGTCAAATCACTTAGGTGGTTTAGAAGGCGGTATGTCAAA 2040

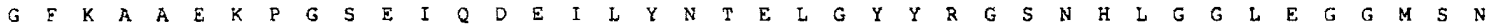
TGGAATGCCAATTATCGTTAATGGTGTAATGAAACCAATTCCAACGTTATATAAACCATTAAATTCAGTAGACATTAATACTAAAGAAGACTTTAAAGCAACAATTGAACGTTCTGATAG 2160 $\begin{array}{llllllllllllllllllllllllllllllllllllllllll}G & M & P & I & I & V & N & G & V & M & K & P & I & P & T & L & Y & K & P & L & N & S & V & D & I & N & T & K & E & D & E & K & A & T & I & E & R & S & D & S\end{array}$ TTGTGCTGTTCCTGCAGCAAGTATCGTCTGTGAACATGTCGTAGCATTTGAAATTGCAAAAGCATTATTGGAAGAATTCCAATCAAATCATATTGAGCAACTTAAACACAAATTATTGA 2280

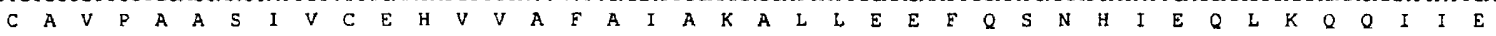

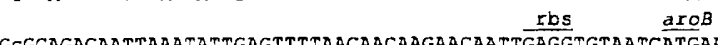

CAGACAATTAAATATTGAGTTTTAACAACAAGAACAATTGAGGTGTAATCATGAAATTACAAACAACATACCCTTCAAACAATTATCCAATATATGTTGAACACGGTGCAATCAAGT

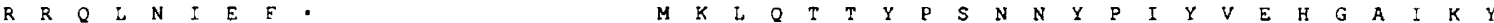

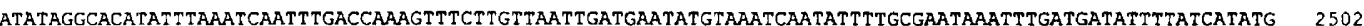

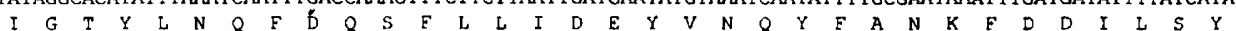

Fig. 2. Nucleotide sequence of the aroC-ndk region of $S$. aureus. The 2502 bp region shows the predicted amino acid sequences for part of gerCC, the entire $n d k$ and aroC genes and part of the aroB gene. Putative promoters for the expression of $n d k$ and aro $C$ are indicated in addition to ribosome binding sites (rbs).

preceded the $n d k$ gene and had homology with the $\operatorname{ger} C C$ gene product from $B$. subtilis.

\section{Evidence for the presence of gerCA and gerCB upstream from gerCC}

To examine the possibility that the $\operatorname{ger} C A$ and $\operatorname{ger} C B$ genes immediately preceded gerCC and to confirm the partial $3^{\prime}$ ORF as gerCC, selected radiolabelled fragments from pMAY1 were hybridized against $S$. aureus DNA using reduced stringency conditions. The plasmid pMAY1 contains the gerCAgerCBgerCC operon from $B$. subtilis (Yazdi, 1991; Henner, 1992). To confirm that the partial 3' ORF upstream from $n d k$ was gerCC, blots were probed with an 843 bp DraI-HindIII gerCC fragment from pMAY1 (Fig. 3). These blots were then compared with blots and to a restriction map previously generated from probing experiments using the aro $C$ gene from $S$. aureus. These blots were found to produce the expected restriction pattern for the gerCC gene being located immediately upstream from $n d k$. Separate $\operatorname{ger} C A, \operatorname{ger} C A B$ and $\operatorname{ger} C A B C$ probes were then prepared from pMAY1 and their hybridization pattern against $S$. aureus DNA was used to establish that the $\operatorname{ger} C A$ and $\operatorname{ger} C B$ genes were located directly upstream from $\operatorname{ger} C C$ (data not shown). The approximate locations of the ger $C$ genes are indicated in Fig. 1.

In B. subtilis the aroFBH genes form the start of an aro-trparo supraoperon of 13 genes involved in the biosynthesis and transport of aromatic amino acids. The aroFBH genes 


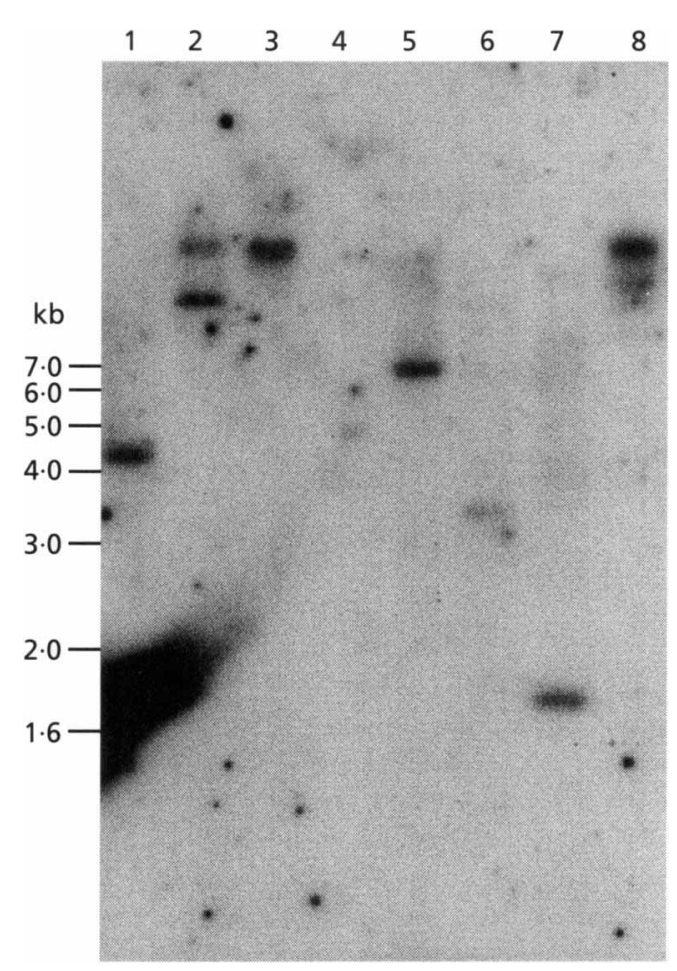

Fig. 3. Southern blot of $S$. aureus 601055 DNA probed with a gerCC fragment from $B$. subtilis. Digested genomic DNA was probed with an $843 \mathrm{bp}$ Dral-Hindlll gerCC fragment from pMAY1. Lanes 1-8: DNA digested with Accl, BamHl, Bg/ll, Clal, EcoRI, Hincll, HindIII and Kpnl, respectively.

are preceded by che $\mathrm{R}$, ndk and the $\operatorname{ger} C A B C$ operon (Henner et al., 1990). Physical mapping experiments with $S$. aureus have shown that $\operatorname{aro} A$ (and thus $\operatorname{aro} B$ and aro $C$ ) are linked to $\operatorname{tyr} B$ (O'Connell et al., 1993) while the trp operon is linked to $\operatorname{tyr} A$ (Pattee et al., 1990) which maps some distance from tyr $B$. Although no similar aro-trp-aro supraoperon exists in $S$. aureus, it has been demonstrated here that the $n d k$ and gerC AgerCBgerCC genes are situated upstream from the aro $C$ and $a r o B$ genes, indicating gene organization similarities with $B$. subtilis (Fig. 1). The che $R$ gene situated between $n d k$ and aroF in $B$. subtlis was not observed in $S$. aureus. Che $R$ encodes a receptor-methylating enzyme involved in motility and the absence of this gene in $S$. aureus is likely to be a consequence of its nonmotility. Nucleoside diphosphate kinases (NDP kinases), encoded by $n d k$, are well studied enzymes that catalyse the transfer of the $\gamma$-phosphate of nucleoside triphosphates to nucleoside diphosphates. The observed linkage between the ger $C$ genes and the aro genes in both organisms may have a functional explanation. The ger $C C$ gene from $B$. subtilis shares a high degree of identity $(65 \%)$ with the ORF-3 gene encoding one subunit of heptaprenyl pyrophosphate synthetase from $B$. stearothermophilus. This enzyme has been shown to have a role in the synthesis of the prenyl side-chain of the menaquinone nucleus (KoikeTakeshita et al., 1995; Takahashi et al., 1980). Menaquinone biosynthesis branches from chorismate and the grouping of the aro genes with the ger $C$ genes may merely

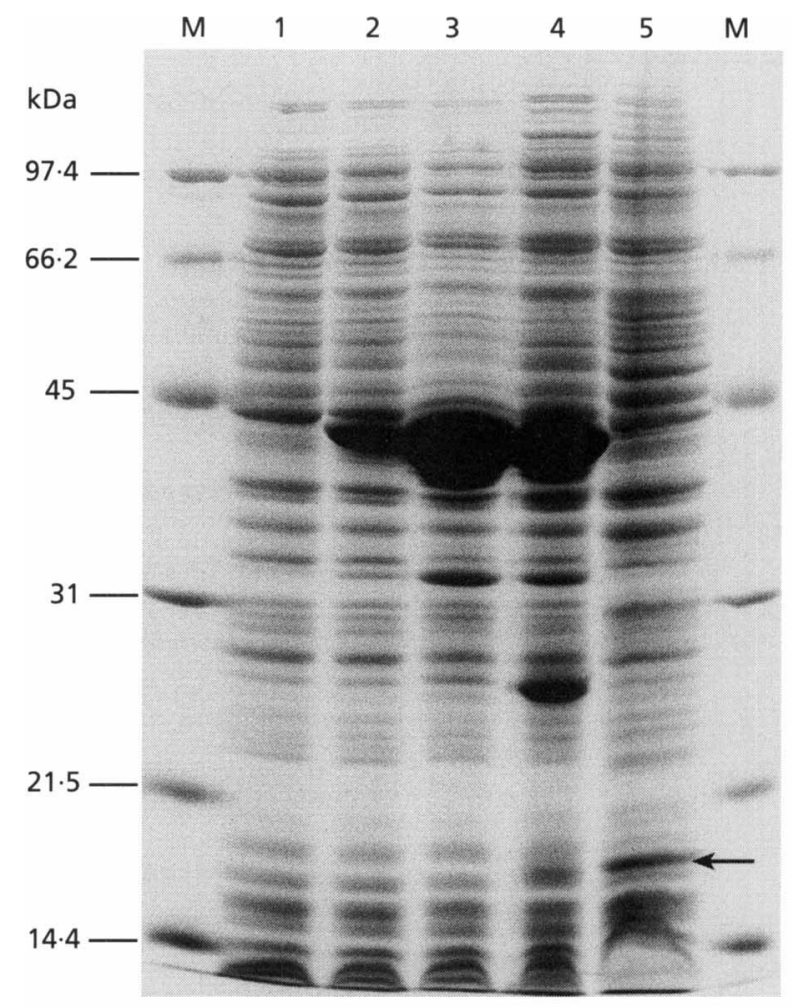

Fig. 4. Protein expression from E. coli strains containing the aroC clones, pMJH7EX2 and pMJH701. Proteins were analysed by SDS-PAGE. Lanes: $M$, molecular mass markers; 1 , GLW40(DE3) control; 2, GLW40(DE3)(pMJH7EX2) before induction with IPTG; 3, GLW40(DE3)(pMJH7EX2) $5 \mathrm{~h}$ after induction with IPTG; 4, GLW40(DE3)(pMJH7EX2pLysS) $5 \mathrm{~h}$ after induction with IPTG (the $28 \mathrm{kDa}$ band is T7 lysozyme which is expressed from pLysS and reduces the basal level of activity of T7 RNA polymerase); 5, pMJH701 in $E$. coli $\mathrm{DH} 5 \alpha$ with arrow showing Ndk expression.

reflect the greater clustering of aromatic pathway genes in these organisms.

\section{Overexpression of chorismate synthase}

The overexpression of $S$. aureus chorismate synthase was accomplished by amplifying the coding region using PCR and cloning the gene into the $\mathrm{T} 7$ expression plasmid, pTB361. The gene was sequenced and found to match the template sequence. The expression plasmid produced, pMJH7EX2, was transformed into the E. coli strains BL21(DE3) and GLW40(DE3) and expression initiated with the addition of IPTG. When expression was monitored by SDS-PAGE, two new bands of 43 and $33 \mathrm{kDa}$ were observed when compared to the control (Fig. 4). The $43 \mathrm{kDa}$ band had an $\mathrm{N}$-terminal sequence (MRYLTSGESHGPQLTVIVEGVPANLEVK) which matched the predicted translation for the start of the aroC gene. The N-terminal sequence of the $33 \mathrm{kDa}$ band (MKRTITKPRPGHADLVGGMK) matched an internal region of the predicted chorismate synthase sequence. The $33 \mathrm{kDa}$ band is postulated to arise from a translational start event within the mRNA as this sequence corresponds 


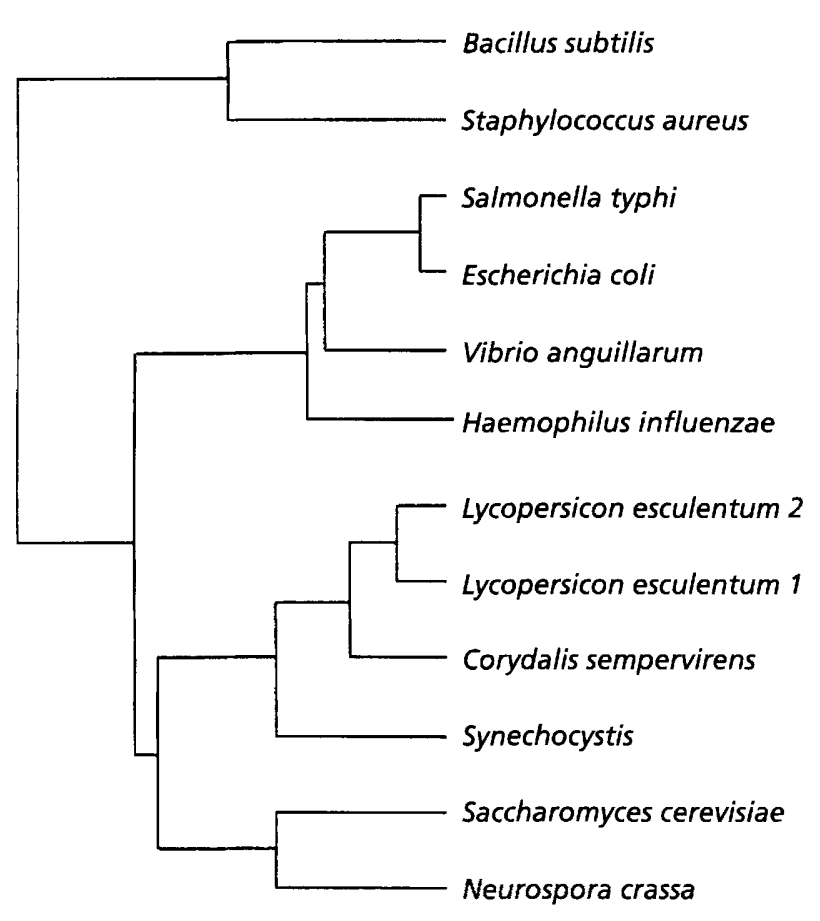

Fig. 5. Dendrogram showing relative amino acid sequence similarity among chorismate synthases from different organisms. The diagram was derived from the GCG multiplealignment program PILEUP. This is not a precise evolutionary tree but is likely to reflect evolutionary relationships (Milkman, 1994).

to a start position downstream from a weak putative ribosome binding site (GAG).

\section{Sequence comparison and immunoblotting of $S$. aureus chorismate synthase}

Chorismate synthase from $S$. aureus shows a high degree of sequence similarity with the enzyme from $B$. subtilis. A dendrogram produced from an alignment of known chorismate synthase sequences (Fig. 5) revealed that the $S$. aureus and $B$. subtilis enzymes form a sequence group which is distinct from that formed by other bacterial, plant and fungal sequences. This difference between the $S$. aureus enzyme and other chorismate synthases was further demonstrated with immunoblotting. Antibodies raised against chorismate synthase from $E$. coli or $C$. sempervirens have previously been shown to possess strong interspecies cross-reactivity with chorismate synthases from a number of plants and micro-organisms (Schaller et al., 1991). Chorismate synthase from S. aureus, however, showed no detectable immunological cross-reactivity with antibodies raised against $E$. coli chorismate synthase (data not shown).

\section{Purification and properties of chorismate synthase}

S. aureus chorismate synthase was purified more than 7-fold from E. coli GLW40(DE3)(pMJH7EX2) to give around $100 \mathrm{mg}$ of enzyme (Table 1) with a purity of $\geqslant 95 \%$ purity as judged by SDS-PAGE. The subunit molecular mass of the enzyme was determined to be $43024 \mathrm{Da}$ (in good agreement with the calculated molecular mass of 43026) by electrospray mass spectrometry and the native molecular mass was determined to be $186800 \mathrm{Da} \pm 7000$ by gel filtration. The enzyme, when expressed in and isolated from $E$. coli, is therefore a homotetramer similar to the E. coli enzyme (White et al., 1988 ) but different to that from B. subtilis which forms a heterotrimer with 3-dehydroquinate synthase and a flavin reductase (Hasan \& Nester, 1978). The apparent $K_{\mathrm{m}}$ and the specific activity of the $S$. aureus enzyme were measured using the assay conditions described in Methods. The apparent $K_{\mathrm{m}}$ value for EPSP was $12 \cdot 7 \mu \mathrm{M}$, which is broadly similar to that of other chorismate synthases studied. The apparent $K_{\mathrm{m}}$ of FMN for the $S$. aureus enzyme was determined to be $4 \cdot 8 \mu \mathrm{M}$. This is similar to that for the $B$. subtilis chorismate synthase $(12.7 \mu \mathrm{M})$ (Hasan \& Nester, 1978). However, both enzymes appear to bind FMN much less tightly than other chorismate synthases studied. The apparent $K_{\mathrm{m}}$ values for the Eu. gracilis, $N$. crassa, and $C$. sempervirens chorismate synthases are $76 \mathrm{nM}, 66 \mathrm{nM}$ and $37 \mathrm{nM}$, respectively (Schaller et al., 1991). S. aureus chorismate synthase was observed to exhibit maximum specific activity $\left(4 \cdot 0 \mu \mathrm{mol} \mathrm{min} \mathrm{mg}^{-1} \mathrm{mg}^{-1}\right)$ with reduced FMN as cofactor. FAD and riboflavin were capable of substituting for FMN but the relative levels of activity observed $(13 \%$ and $2.4 \%$, respectively, in the standard assay) were much lower than those reported for the enzymes from $E u$. gracilis, $N$. crassa, $C$. sempervirens and E. coli (73-84\% for FAD and 14-39\% for riboflavin) (Schaller et al., 1991).

\section{ACKNOWLEDGEMENTS}

We thank Wright Nichols (Zeneca Pharmaceuticals) for helpful discussions, Veer Math for the supply of synthetic oligonucleotides, Janice Young (Zeneca Pharmaceuticals) for $\mathrm{N}$ terminal protein sequencing and Anne Moir (University of Sheffield) for pMAY1 and helpful discussions. We thank Zeneca Pharmaceuticals Ltd and the BBSRC for a CASE studentship for M. J.H. T.J.F would like to acknowledge the Wellcome Trust for funding.

Table 1. Purification of $S$. aureus chorismate synthase

\begin{tabular}{|lccccc|}
\hline Step & $\begin{array}{c}\text { Total protein } \\
(\mathbf{m g})\end{array}$ & $\begin{array}{c}\text { Total activity } \\
\mathbf{( U )}\end{array}$ & $\begin{array}{c}\text { Specific activity } \\
\left(\mathbf{U} \mathbf{~ m g}^{-1}\right)\end{array}$ & $\begin{array}{c}\text { Yield } \\
(\mathbf{\%})\end{array}$ & $\begin{array}{c}\text { Purification } \\
\text { (-fold) }\end{array}$ \\
\hline Crude extract & 1210 & 416 & $0 \cdot 34$ & 100 & 1 \\
DEAE-Sephacel & 592 & 317 & $0 \cdot 54$ & 76 & $1 \cdot 6$ \\
Cellulose phosphate & $98 \cdot 5$ & 248 & $2 \cdot 5$ & 60 & $7 \cdot 4$ \\
\hline
\end{tabular}




\section{REFERENCES}

Bentley, R. (1990). The shikimate pathway - a metabolic tree with many branches. Crit Rev Biochem Mol Biol 25, 307--384.

Bornemann, S., Balasubramanian, S., Coggins, J. R., Abell, C., Lowe, D. J. \& Thorneley, R. N. F. (1995). Escherichia coli chorismate synthase: a deuterium kinetic-isotope effect under single-turnover conditions shows that a flavin intermediate forms before the $\mathrm{C}$ (6proR)-H bond is cleaved. Biochem J 305, 707-710.

Bowe, F., O'Gaora, P., Maskell, D., Cafferkey, M. \& Dougan, G. (1989). Virulence, persistence, and immunogenicity of Yersinia enterocolitica $\mathrm{O}: 8$ aro $A$ mutants. Infect Immun 57, 3234-3236.

Bradford, M. M. (1976). A rapid and sensitive method for the quantitation of microgram quantities of protein utilizing the principle of protein-dye binding. Anal Biochem 72, 248-254.

Brockbank, S. M. V. \& Barth, P. T. (1993). Cloning, sequencing and expression of the DNA gyrase genes from Stapbylcoccus aureus. J Bacteriol 175, 3269-3277.

Davies, G. M., Barrett-Bee, K. J., Jude, D. A., Lehan, M., Nichols, W. W., Pinder, P. E., Thain, J. L., Watkins, W. J. \& Wilson, R. G. (1994). (6S)-6-Fluoroshikimic acid, an antibacterial agent acting on the aromatic biosynthetic pathway. Antimicrob Agents Chemother 38 , 403-406.

Ewart, C. D. C., Jude, D. A., Thain, J. L. \& Nichols, W. W. (1995). Frequency and mechanism of resistance to antibacterial action of ZM 240401, (6S)-6-fluoro-shikimic acid. Antimicrob Agents Chemother 39, 87-93.

Gaertner, F. H. \& Cole, K. W. (1973). Properties of chorismate synthase in Neurospora crassa. J Biol Chem 248, 4602-4909.

Gill, S. C. \& von Hippel, P. H. (1989). Calculation of protein extinction coefficients from amino acid sequence data. Anal Biochem 182, 319-326.

Hasan, N. \& Nester, E. W. (1978). Purification and properties of chorismate synthase from Bacillus subtilis. J Biol Chem 253, 49934998.

Haslam, E. (1993). Shikimic Acid: Metabolism and Metabolites. Chichester: John Wiley \& Sons.

Henner, D. (1992). gerC AgerCBgerCC, ndk, cheR, aroFaroBaroH nucleotide sequence. Genbank accession no. M80245.

Henner, D. J., Gollnick, P. \& Moir, A. (1990). Analysis of an 18 kilobase pair region of the Bacillus subtilis chromosome containing the $m$ tr and gerC operons and the aro-trp-aro supraoperon. In 6 th International Symposium on Genetics of Industrial Microorganisms, pp. 657-665. Edited by H. Heslot, J. Davies, J. Florent, L. Bobichon, G. Durand \& L. Penasse. Strasbourg: Societe Francaise de Microbiologie.

Henstrand, J. M., Amrhein, N. \& Schmid, J. (1995). Cloning and characterization of a heterologously expressed bifunctional chorismate synthase/flavin reductase from Neurospora crassa. J Biol Chem 270, 20447-20452.

Hoiseth, S. K. \& Stocker, B. A. D. (1981). Aromatic-dependent Salmonella typhimurium are non-virulent and are effective live vaccines. Nature 241, 238-239.

Holmes, D. S. \& Quigley, M. (1981). A rapid boiling method for the preparation of bacterial plasmids. Anal Biochem 114, 193

Ivins, B. E., Welkos, S. L., Knudson, G. B. \& Little, S. F. (1990). Immunization against anthrax with aromatic compound-dependent $\left(\right.$ Aro $\left.^{-}\right)$mutants of Bacillus antbracis and with recombinant strains of Bacillus subtilis that produce anthrax protective antigen. Infect Immun 58, 303-308.
Jones, P. W., Dougan, G., Haywood, C., Mackensie, N., Collins, P. \& Chatfield, S. N. (1991). Oral vaccination of calves against experimental salmenellosis using a double aro mutant of Salmonella typhimurium. Vaccine 9, 29-33.

Koike-Takeshita, A., Koyama, T., Obata, S. \& Ogura, K. (1995). Molecular cloning and nucleotide sequences of the genes for two essential proteins constituting a novel enzyme system for heptaprenyl diphosphate synthesis. J Biol Chem 270, 18396-18400.

Krell, T., Pitt, A. R. \& Coggins, J. R. (1995). The use of electrospray mass spectrometry to identify an essential arginine residue in type II dehydroquinases. FEBS Lett 360, 93-96.

Matsudaira, P. (1987). Sequence from picomole quantities of proteins electroblotted onto polyvinylidene difluoride membranes. J Biol Chem 262, 10035-10038.

Milkman, R. (1994). An Escherichia coli homologue of eukaryotic potassium channel protein. Proc Natl Acad Sci US A 91, 3510-3514.

Mousdale, D. M. \& Coggins, J. R. (1986). Detection and subcellular localization of a higher plant chorismate synthase. FEBS Lett 205 , 328-332.

O'Connell, C., Pattee, P. \& Foster, T. J. (1993). Sequence and mapping of the aro A gene of Staphylococcus aureus 8325-4. I Gen Microbiol 139, 1449-1460.

Pattee, P. A., Lee, H. \& Bannantine, J. P. (1990). Genetic and physical mapping of the chromosome of Staphylococcus aureus. In Molecular Biology of the Staphylococci, pp. 41-58. Edited by R. P. Novick. New York: VCH Publishers.

Pittard, A. J. \& Wallace, B. J. (1966). Distribution and function of genes concerned with aromatic biosynthesis in Escherichia coli. J Bacteriol 91, 1494-1508.

Ramjee, M. K., Coggins, J. R., Hawkes, T. R., Lowe, D. J. \& Thorneley, R. N. F. (1991). Spectrophotometric detection of a modified flavin mononucleotide intermediate formed during the catalytic cycle of chorismate synthase. $J$ Am Chem Soc 113, 8566-8567.

Ramjee, M. K., Coggins, J. R. \& Thorneley, R. N. F. (1994). A continuous, anaerobic spectrophotometric assay for chorismate synthase activity that utilizes photoreduced flavin mononucleotide. Anal Biochem 220, 137-141.

Roberts, M., Maskell, D., Novotny, P. \& Dougan, G. (1990). Construction and characterization in vivo of Bordetella pertussis aro $A$ mutants. Infect Immun 58, 732-739.

Sambrook, J., Fritsch, E. F. \& Maniatis, T. (1989). Molecular Cloning: a Laboratory Manual. Cold Spring Harbor, NY: Cold Spring Harbor Laboratory.

Sanger, F., Nicklen, S. \& Coulson, A. R. (1977). DNA sequencing with chain terminating inhibitors. Proc Natl Acad Sci USA 74, 5463-5467.

Schaller, A., Windhofer, V. \& Amrhein, N. (1990). Purification of chorismate synthase from a cell culture of the higher plant Corydalis sempervirens Pers. Arch Biochem Biophys 282, 437-442.

Schaller, A., Afferden, M., Windhofer, V., Bulow, S., Abel, C., Schmid, J. \& Amrhein, N. (1991). Purification and characterization of chorismate synthase from Euglena gracilis. Plant Physiol 97, 1271-1279.

Short, J. M., Fernandez, J. M., Sorge, J. A. \& Hause, W. D. (1988). AZAP: a bacteriophage $\lambda$ expression vector with in vivo excision properties. Nucleic Acids Res 16, 7583-7600.

Studier, F. W. \& Moffatt, B. A. (1986). Use of bacteriophage T7 RNA polymerase to direct selective high-level expression of cloned genes. J Mol Biol 189, 113-130. 
Takahashi, I., Ogura, K. \& Seto, S. (1980). Heptaprenyl pyrophosphate synthetase from Bacillus subtilis. J Biol Chem 255, 4539-4543.

Vaughan, L. M., Smith, P. R. \& Foster, T. J. (1993). An aromaticdependent mutant of the fish pathogen Aeromonas salmonicida is attenuated in fish and is effective as a live vaccine against the salmonid disease furunculosis. Infect Immun 61, 2172-2181.

Walker, G. E., Dunbar, B., Hunter, I. S., Nimmo, H. G. \& Coggins, J. R. (1996). Evidence for a novel class of microbial 3-deoxy-Darabino-heptulosonate-7-phosphate synthase in Streptomyces coelicolor A3(2), Streptomyces rimosus and Neurospora crassa. Microbiology 142, 1973-1982.
White, P. J., Millar, G. \& Coggins, J. R. (1988). The overexpression, purification and complete amino acid sequence of chorismate synthase from Escherichia coli $\mathrm{K} 12$ and its comparison with the enzyme from Neurospora crassa. Biocbem J 251, 313-322.

Yanisch-Perron, C., Vieira, J. \& Messing, J. (1985). Improved M13 phage cloning vectors and host strains: nucleotide sequences of the M13mp18 and pUC19 vectors. Gene 33, 103-119.

Yazdi, M. A. (1991). Genetic and molecular analysis of the gerC spore germination locus of Bacillus subtilis 168 . PhD Thesis. University of Sheffield, Sheffield, UK.

Received 21 February 1996; revised 29 May 1996; accepted 11 June 1996. 